\title{
Kinetic and thermodynamic analysis of the role of start codon/anticodon base pairing during eukaryotic translation initiation
}

\author{
SARAH E. KOLITZ, JULIE E. TAKACS, and JON R. LORSCH ${ }^{\mathbf{1}}$ \\ Department of Biophysics and Biophysical Chemistry, Johns Hopkins University School of Medicine, Baltimore, Maryland 21205, USA
}

\begin{abstract}
Start codon recognition is a crucial event in the initiation of protein synthesis. To gain insight into the mechanism of start codon recognition in eukaryotes, we used a yeast reconstituted initiation system to isolate the step of Met-tRNA $A_{i} \bullet$ IF $2 \bullet G T P$ ternary complex (TC) binding to the $40 \mathrm{~S}$ subunit. We examined the kinetics and thermodynamics of this step in the presence of base changes in the mRNA start codon and initiator methionyl tRNA anticodon, in order to investigate the effects of base pairing and sequence on the stability of the resulting 43S•mRNA complex. We observed that the formation of three base pairs, rather than their identities, was the key determinant of stability of TC binding, indicating that nothing is inherently special about the sequence AUG for this step. Surprisingly, the rate constant for TC binding to the 40S subunit was strongly codon dependent, whereas the rate constant for TC dissociation from the 43S॰mRNA complex was not. The data suggest a model in which, after the initial diffusion-limited encounter of TC with the $40 \mathrm{~S}$ subunit, the formation of three matching start codon/anticodon base pairs triggers a conformational change that locks the complex into a stable state. This induced-fit mechanism supports the proposal that initiation codon recognition by the 435 complex induces a conformational change from an open state to a closed one that arrests movement along the mRNA.
\end{abstract}

Keywords: translation initiation; protein synthesis; initiation factors; kinetics; thermodynamics; ribosome

\section{INTRODUCTION}

Translation initiation in eukaryotes is an extremely complicated process, involving at least 12 initiation factors made up of at least 23 polypeptide chains. The goal of initiation is to assemble an $80 \mathrm{~S}$ ribosomal complex at the correct location on the mRNA to be translated, with the anticodon of the initiator tRNA base-paired to the mRNA start codon in the $\mathrm{P}$ site of the ribosome. The process begins when the methionyl initiator tRNA (Met-tRNA ${ }_{i}$ ) binds GTP-bound eukaryotic initiation factor (eIF) 2, forming a ternary complex (TC). TC binds to the $40 \mathrm{~S}$ ribosomal subunit, with the help of eIFs 1 and 1A, to form a $43 \mathrm{~S}$ complex. The $43 \mathrm{~S}$ complex binds the mRNA near the $5^{\prime}$-7-methylguanosine cap in a process facilitated by eIF3, eIF4F, and the poly(A) binding protein, and is thought to

${ }^{1}$ Reprint requests to: Jon R. Lorsch, Department of Biophysics and Biophysical Chemistry, Johns Hopkins University School of Medicine, Baltimore, Maryland 21205, USA; e-mail: jlorsch@jhmi.edu; fax: (410) 955-0637.

Article published online ahead of print. Article and publication date are at http://www.rnajournal.org/cgi/doi/10.1261/rna.1318509. scan along the mRNA in search of the start codon. Once the start codon is located, eIF2 is converted to its GDPbound form, committing the complex to initiation at that location. eIF2•GDP dissociation and $60 \mathrm{~S}$ subunit joining can then take place, creating the final $80 \mathrm{~S}$ initiation complex (for reviews of eukaryotic translation initiation, see Kapp and Lorsch 2004b; Pestova et al. 2007).

Accurate start codon selection is essential, because beginning translation in the wrong place will not produce the desired protein, and could create an aberrant, possibly toxic one. In eukaryotes, the start codon is nearly always AUG. The correct AUG must be chosen out of a sea of near-cognate codons in the mRNA, and even over other AUG codons. The correct AUG is usually the 5' -most AUG in the mRNA; thus the scanning model would seem to explain how this AUG is preferentially located over other AUG codons (Kozak 1978, 2002). Sequence context can also play a role in identifying the correct start codon (Kozak 1986; Pisarev et al. 2006), but the mechanism for this effect is not entirely clear. Recent studies have shed light on a number of the molecular events surrounding start-site selection and on how the $43 \mathrm{~S}$ preinitiation 
complex becomes committed to initiation at a particular location (Pestova et al. 1998; Pestova and Kolupaeva 2002; Algire et al. 2005; Maag et al. 2005; Cheung et al. 2007; Fekete et al. 2007; for review, see Algire and Lorsch 2006; Mitchell and Lorsch 2008).

Previous work indicates that the start codon/anticodon interaction helps to situate the ribosome at the appropriate location to begin translation (Cigan et al. 1988). The effects of base pairing between an initiator tRNA anticodon and mRNA start codon bearing compensatory changes have been examined for several pairs in vivo (Cigan et al. 1988; Drabkin and RajBhandary 1998). In addition, one such pair was examined in a mammalian reconstituted system using primer extension to monitor preinitiation complex engagement at the start codon (Lomakin et al. 2006). These studies demonstrated that a matching start codon/anticodon pair other than AUG/CAU could provide some ability to initiate translation. The present work aimed to build on these studies, using a Saccharomyces cerevisiae reconstituted initiation system to isolate and probe the energetics of the start codon/anticodon interaction as it contributes to TC binding to the $40 \mathrm{~S}$ ribosomal subunit. Isolation of this step using the reconstituted system allowed a detailed examination of a complete set of start codon and anticodon changes, both for their intrinsic effects on TC binding and for the ability of compensatory mutations to restore this interaction. By systematically changing bases in the mRNA start codon and the tRNA anticodon, we endeavored to determine the effects of sequence versus base pairing in dictating interactions in the 43S•mRNA preinitiation complex that could be crucial for start-site selection.

\section{RESULTS}

\section{Start codon changes can affect the binding of mRNA to the $40 S$ subunit}

We used a short, unstructured model mRNA [GGAA $(\mathrm{UC})_{7} \mathrm{UAUG}(\mathrm{CU})_{10} \mathrm{C}$ ] [denoted mRNA(AUG)], circumventing the need for mRNA recruitment and remodeling factors (Algire et al. 2002). This model mRNA was modified to create nine mRNAs bearing each single-base change in the start codon. [Each is denoted here by its start codon, e.g., mRNA(CUG) refers to the model mRNA with a CUG codon in place of AUG.]

The affinity of the model mRNAs for the 40S ribosomal subunit in the absence of tRNA and initiation factors was determined using a fluorescence-based competition assay with a pyrene-labeled mRNA (Studer et al. 2003). Pyrenelabeled mRNA was bound to the $40 \mathrm{~S}$ subunit, then competed off by titrating in unlabeled model mRNA (Maag et al. 2005). The pyrene-labeled mRNA fluoresces significantly more strongly when bound to the $40 \mathrm{~S}$ subunit than when free in solution; thus, binding of the unlabeled mRNA is observed as a decrease in fluorescence.
A $K_{\mathrm{d}}$ of $2.7 \pm 0.5 \mu \mathrm{M}$ was determined for mRNA(AUG) binding to the $40 \mathrm{~S}$ subunit (Fig. 1; Table 1). This affinity was unaffected by the addition of saturating eIFs 1 and $1 \mathrm{~A}$, consistent with previous findings (Maag et al. 2005). Most single-base start codon changes had little effect on $K_{\mathrm{d}}$. One substitution (an A in the second position) resulted in an increase in affinity; binding of mRNA(AAG) was about twofold tighter than binding of mRNA(AUG), with a $K_{\mathrm{d}}$ of $1.4 \pm 0.04 \mu \mathrm{M}$. In each position of the start codon, one base substitution was detrimental to binding, showing an approximately twofold decrease in affinity. This base was different for each position. At a position held in AUG by a purine, the "bad" base was a pyrimidine, and vice versa. Changing two bases was worse than changing one, as a model mRNA containing a CUC codon in place of AUG [GGAA(UC) $\left.{ }_{19} \mathrm{U}\right]$ had an approximately fourfold weaker affinity than mRNA(AUG) $(12 \pm 2 \mu \mathrm{M})$. Three mRNAs [mRNA(AUG), mRNA(AUU), and mRNA(CUC)] were studied prior to this work and the $K_{\mathrm{d}}$ 's determined here agree well with the previously published data (Maag et al. 2005). Thus, with a model mRNA, the ribosome shows some inherent preference for mRNA sequence independent of the presence of $t R N A_{i}$, although this preference is not specific for the AUG codon.

\section{Single-base start codon changes affect the affinity of TC for the $40 S$ subunit}

We next examined the effect of single-base changes to the start codon on the binding affinity of TC for the small

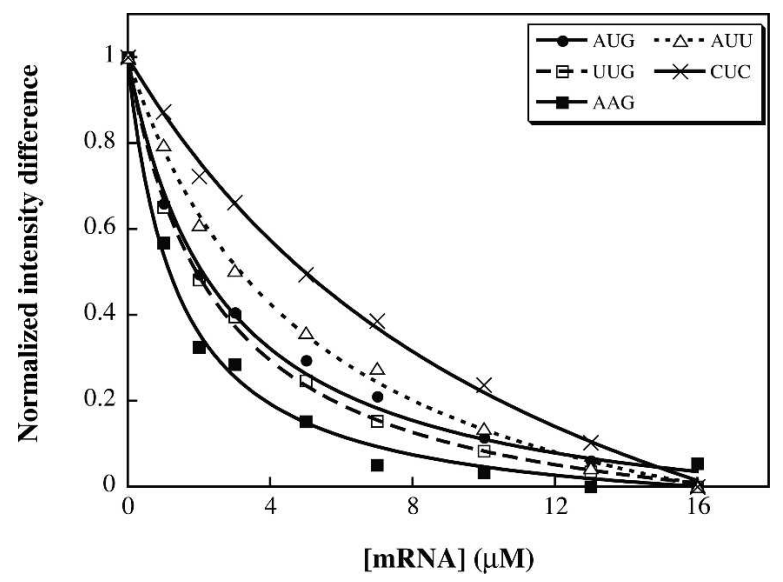

FIGURE 1. Base changes in the start codon of a model mRNA affect its affinity for the $40 \mathrm{~S}$ subunit. mRNA(AUG) $(\bullet)$ and mRNA(UUG) ( $\square$ ) bind to the $40 \mathrm{~S}$ subunit with similar affinity. One mRNA, mRNA(AAG) (-), binds twofold more tightly. mRNA(AUU) $(\Delta)$ has a twofold reduction in affinity compared to mRNA(AUG), while an mRNA bearing two base changes, mRNA(CUC) $(X)$, has a fourfold reduction in affinity compared to mRNA(AUG). Each curve is the average of at least two experiments. Fluorescence data were processed as described in Materials and Methods. $K_{\mathrm{d}}$ 's derived from these data are given in Table 1. 
TABLE 1. Affinity of mRNA for the $40 \mathrm{~S}$ subunit

\begin{tabular}{lc}
\hline Codon & $\begin{array}{c}K_{\mathrm{d}} \\
(\mu \mathrm{M})\end{array}$ \\
\hline AUG & $2.7 \pm 0.5$ \\
CUG & $4.9 \pm 0.03$ \\
GUG & $2.6 \pm 0.1^{\mathrm{a}}$ \\
UUG & $2.9 \pm 0.1$ \\
AAG & $1.4 \pm 0.04$ \\
ACG & $2.7 \pm 0.3$ \\
AGG & $4.3 \pm 0.9$ \\
AUA & $2.8 \pm 0.6$ \\
AUC & $2.7 \pm 0.1$ \\
AUU & $6.2 \pm 1.4$ \\
CUC & $12 \pm 2$ \\
\hline
\end{tabular}

Values are the averages of at least two independent experiments. Errors are average deviations.

aThis mRNA also contains a CUG codon that was inadvertently introduced by the change of AUG to GUG, which could contribute to the apparent affinity.

ribosomal subunit in the presence of saturating eIFs 1 and 1A. The strength of the coupling between binding of TC and mRNA to the $40 \mathrm{~S}$ subunit is a read-out of interactions occurring in the complex that are likely to be involved in start codon recognition.

We measured the affinity of TC for the $40 \mathrm{~S}$ subunit in the presence of each changed mRNA, using a native gel assay monitoring ${ }^{35} \mathrm{~S}$-methionine-charged initiator tRNA (Algire et al. 2002). Measuring the fraction of TC bound to the $40 \mathrm{~S}$ subunit as a function of $40 \mathrm{~S}$ subunit concentration allowed $K_{\mathrm{d}}$ values to be determined. Base changes in the first position of the start codon were tolerated (Fig. 2A), whereas any change in the second or third position of the start codon resulted in significantly weakened binding (Fig. $2 \mathrm{~B}, \mathrm{C})$. The $K_{\mathrm{d}}$ values are summarized in Table 2. This pattern contrasts with the "wobble position" rule in the A site of the ribosome during the elongation phase of protein synthesis, where the third base of the codon being read (the "wobble") tolerates change more readily than other positions (Crick 1966); it is, however, strikingly similar in character.

The $K_{\mathrm{d}}$ values determined here for mRNA(AUG) and mRNA(AUU) and without mRNA are in agreement with the values previously determined in our laboratory (Maag et al. 2005). That work also showed that changing two bases in the start codon [mRNA(CUC)] results in the same $K_{\mathrm{d}}$ for TC binding to the $40 \mathrm{~S}$ subunit as does leaving out the mRNA entirely.

The strength of TC binding does not show any clear correlation with the number of $\mathrm{G}-\mathrm{C}$ base pairs possible between codon and anticodon, although this effect is difficult to disentangle from the effects of the location of the disrupted base pair in the helix, mismatches in an inner position in a helix often being more disruptive than mismatches on the ends (Kierzek et al. 1999). Base changes in the first and second positions of the start codon remove an $\mathrm{A}-\mathrm{U}$ base pair, whereas changes in the third position remove a G-C base pair. From the hierarchy of $K_{\mathrm{d}}$ values (Table 2), disrupting the $\mathrm{G}-\mathrm{C}$ base pair appears no worse than disrupting the A-U base pair in the middle position, although a larger effect might be expected for disrupting the central base pair in the helix. In general, the effect of the base pair's position in the helix and GC content effects seem to be in the same range, with neither overwhelming the other.

That the presence of a GUG codon instead of an AUG codon allows for tight binding can be rationalized by the possibility that the introduced $\mathrm{G}$ might form a $\mathrm{G}-\mathrm{U}$ wobble pairing with the $\mathrm{U}$ in the anticodon. More surprising is the fact that the UUG codon also allows for tight binding of TC to the 40S subunit. A limitation of the native gel assay is that for very tight binding $(\leq 1 \mathrm{nM})$ the assay yields only an upper limit on the binding affinity; therefore, differences in affinity could exist between first position codon changes that are not detectable by this assay. The $K_{\mathrm{d}}$ in the presence of mRNA(CUG) is also tighter than the limit of detection, but the final fraction bound is only half that with mRNA(AUG). We interpret the endpoint difference to reflect the existence of two forms of the complex, only one of which is stable on the gel (Kapp et al. 2006).

\section{A similar hierarchy of near-cognate start codons is seen for translation in vivo}

We wanted to compare the effects of base changes to the start codon on TC binding affinity to the efficiency of use of these near-cognate codons in the initiation of translation. Previous in vivo and in vitro studies of the efficiency of use of AUG versus near-cognate codons have yielded conflicting results (Clements et al. 1988; Donahue and Cigan 1988; Peabody 1989). We therefore reinvestigated the effects of single-base start codon changes in vivo using a dual luciferase reporter system in S. cerevisiae (Cheung et al. 2007). The efficiency of initiation on firefly luciferase mRNA with near-cognate start codons was compared to that with an AUG start codon (both normalized to renilla luciferase activity expressed from a separate promoter as an internal control). Any base change resulted in at least a 14fold reduction in translation (Fig. 3). The hierarchy observed in this in vivo assay was similar to the hierarchy observed in the TC binding studies. In general, base changes in the first position of the start codon allowed for greater levels of translation than changes in the second or third position, although the magnitudes of the differences in vivo were not as large as those seen in the TC binding assay. Changing the $\mathrm{U}$ in the second position to a purine (AAG, AGG) completely abolished detectable translation above background levels. The fact that no activity above background was observed for these codons, as well as for CUC (data not shown), indicates that, although many codons are present upstream and downstream of the start site, no other in-frame codons are used efficiently for 
A

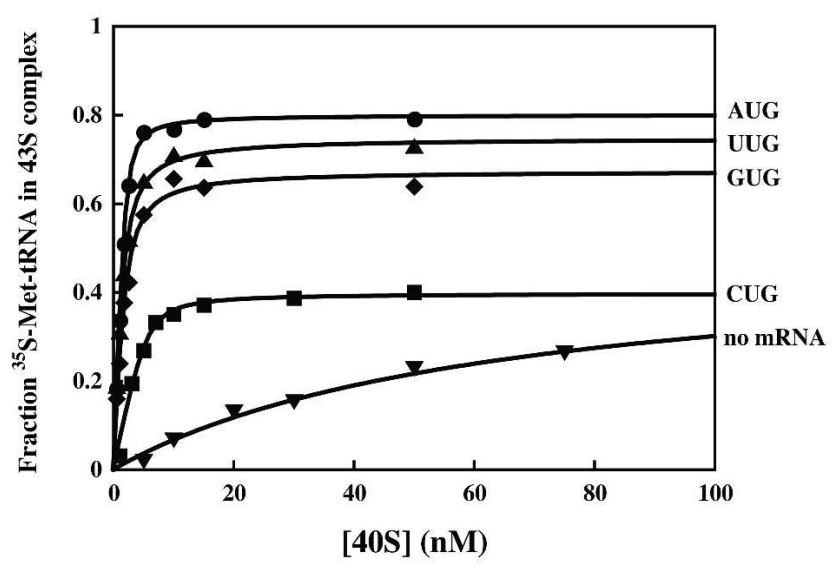

B

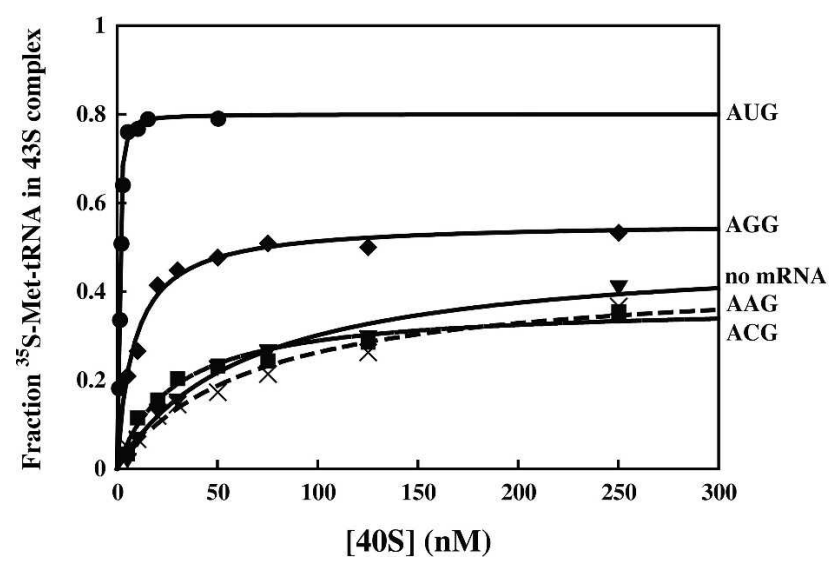

C

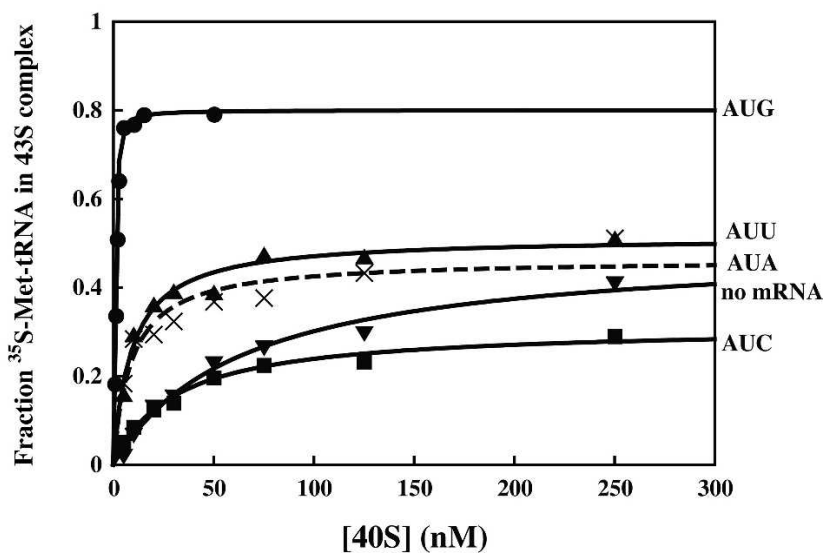

FIGURE 2. The affinity of TC for the $40 \mathrm{~S}$ subunit is affected by single-base changes in the start codon. The first position of the start codon is relatively tolerant of base changes $(A)$ : CUG $(\bullet)$, GUG $(\bullet)$, and UUG $(\boldsymbol{\Delta})$. Any change in the second position $(B)$ : AAG $(\times)$, ACG $(\boldsymbol{\bullet})$, and AGG $(\bullet)$, or third position $(C)$ : AUA $(\times)$, AUC $(\mathbf{-})$, and AUU $(\boldsymbol{\Lambda})$, of the start codon significantly weakens binding. Note the change in scale on the $x$ axis between $(A)$ and $(B)$. Curves for TC binding in the presence of mRNA(AUG) $(\bullet)$ and in the absence of mRNA $(\boldsymbol{\nabla})$ are shown in each panel for comparison. Each curve is the average of at least three independent experiments. Curves were fit as described in Materials and Methods. Apparent $K_{\mathrm{d}}$ values derived from the data are given in Table 2 .

initiation. Changes in the third position were slightly less tolerated than changes in the first position. The same experiment done in a yeast strain $(u p f 1 \Delta)$ deficient for nonsense-mediated decay (nmd) (Culbertson and NeenoEckwall 2005) produced the same results (Fig. 3), indicating that these effects are not due to nonsense-mediated decay of the mRNAs lacking normal start codons.

\section{Rate constants for TC dissociation from the 43S•mRNA complex are similar across codons}

To better understand the effects of codon/anticodon pairing on the preinitiation complex, we began a kinetic investigation by examining the effects of start codon changes on the rate of dissociation of TC from the 43S•mRNA complex. We formed 43S•mRNA complex with ${ }^{35}$ S-labeled Met-tRNA $A_{i}$ and used a chase of excess (at least
300 -fold) unlabeled TC to make dissociation of the labeled complex irreversible. The fraction of labeled TC bound was monitored over time on native gels. The rate of dissociation was measured for a base change in each position of the start codon [mRNA(UUG), mRNA(AAG), mRNA(AUC)] (Fig. 4 ; Table 3$)$. TC dissociation rate constants $\left(k_{\text {off }}\right)$ were similar across these codons, as well as without mRNA. The rate constant for dissociation with mRNA(AUG) was three- to fourfold lower than with the changed mRNAs, and approximately fivefold lower than without mRNA.

The tRNA used in these assays was made by in vitro transcription using T7 RNA polymerase and thus lacked modifications. The experiment was also performed with

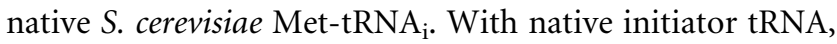
the $k_{\text {off }}$ for TC in the presence of mRNA(AUG) was 0.005 $\mathrm{h}^{-1}, 40$-fold slower than with T7-transcribed tRNA, whereas the $k_{\text {off }}$ values for the two near-cognate codons tested 
TABLE 2. Affinity of wild-type TC for the $40 \mathrm{~S}$ subunit

\begin{tabular}{lcc}
\hline Codon & $\begin{array}{c}\text { Apparent } K_{\mathrm{d}} \\
(\mathrm{nM})\end{array}$ & $\begin{array}{c}\text { Endpoint } \\
\text { (fraction bound) }\end{array}$ \\
\hline AUG & $<1$ & $0.80 \pm 0.03$ \\
CUG & $<1$ & $0.40 \pm 0.01$ \\
GUG & $<1^{\mathrm{a}}$ & $0.67 \pm 0.01^{\mathrm{a}}$ \\
UUG & $<1$ & $0.75 \pm 0.01$ \\
AAG & $67 \pm 17$ & $0.44 \pm 0.07$ \\
ACG & $28 \pm 6.2$ & $0.37 \pm 0.02$ \\
AGG & $8.5 \pm 1.6$ & $0.56 \pm 0.04$ \\
AUA & $9.1 \pm 1.0$ & $0.46 \pm 0.03$ \\
AUC & $31 \pm 8.8$ & $0.31 \pm 0.03$ \\
AUU & $9.2 \pm 2.0$ & $0.51 \pm 0.01$ \\
No mRNA & $67 \pm 12$ & $0.50 \pm 0.05$ \\
\hline
\end{tabular}

The limit of detection of the assay results in an upper bound of 1 $\mathrm{nM}$ for very low $K_{\mathrm{d}}{ }^{\prime} \mathrm{s}$. Values are the averages of at least three independent experiments. Errors are average deviations.

${ }^{a}$ In this case, a CUG codon present in mRNA(GUG), inadvertently introduced by the change of AUG to GUG, could contribute to the apparent affinity [likely, however, to a minimal extent, given the 100 -fold increase in $k_{\text {on }}$ value with mRNA(GUG) over mRNA (CUG) (Table 4)].

[mRNA(UUG), mRNA(GUG)] were unaffected (data not shown). It is intriguing that tRNA modifications made a difference in the presence of the AUG codon but not with other codons. Fine-tuning of tRNA structure or interactions with the rest of the complex by the modifications may therefore play a role in sending signals for start codon recognition.

\section{Rate constants for TC binding to the $40 \mathrm{~S}$ subunit vary strongly by codon}

The similarity (a fourfold range) of dissociation rate constants observed across codons stood in contrast to the strong (greater than 70-fold) differences observed among codons in the TC affinity studies. Since for simple binding $K_{\mathrm{d}}=k_{\text {off }} / k_{\text {on }}$, the dissimilar $K_{\mathrm{d}}$ values but similar $k_{\text {off }}$ values suggested that the second-order rate constant for TC binding $\left(k_{\mathrm{on}}\right)$ might vary by codon.

To determine rate constants for TC binding to the $40 \mathrm{~S}$ subunit, we monitored the kinetics of formation of $43 \mathrm{~S}$ complex using native gels, initiating the reaction with limiting TC containing ${ }^{35} \mathrm{~S}$-labeled Met-tRNA $A_{i}$ and using a chase of excess (at least 300-fold) unlabeled TC to stop association of labeled complex at the desired time point. Time points were loaded within minutes onto a running native gel such that dissociation of labeled TC in the chase prior to gel loading was negligible. We measured the observed pseudofirst-order rate constant $\left(k_{\text {obs }}\right)$ of TC binding to the $40 \mathrm{~S}$ subunit at several different $40 \mathrm{~S}$ subunit concentrations; the $k_{\text {obs }}$ values were then plotted versus the concentration of $40 S$ subunits and fit to a line (Fig. 5). For simple binding, $k_{\mathrm{obs}}=k_{\mathrm{on}}[40 \mathrm{~S}]+k_{\mathrm{off}}$, and thus the slope of a linear plot of $k_{\text {obs }}$ versus [40S] should yield $k_{\text {on }}$ (Johnson 1992).
The rate constant for TC binding to the 40S subunit was highly dependent on the codon present (Table 4). Measurements performed using native Met-tRNA $\mathrm{i}_{\mathrm{i}}$ for several mRNAs [mRNA(AUG), mRNA(GUG), and mRNA(AUU)] showed no significant difference versus T7-transcribed Met-tRNA $_{i}$ (data not shown). Strikingly, the $k_{\text {on }}$ was 1000-fold higher with an AUG codon than without mRNA or with any base change to the second or third positions of the start codon, in contrast to the barely fivefold variation in $k_{\text {off. }}$ Several possibilities could explain this large difference in $k_{\text {on }}$ values. The $40 \mathrm{~S}$ subunit might adopt a different conformation depending on the codon present, and these various conformations are differentially conducive to binding of TC. Another possibility is that after the initial encounter of TC with the $40 \mathrm{~S}$ subunit, which takes place in a diffusion-controlled manner and yields an unstable complex, an event could occur that depends upon the codon and yields a stable $43 \mathrm{~S} \bullet \mathrm{mRNA}$ complex that can be observed in the gel assay. For example, a codon-dependent conformational change might occur that results in a stable complex.

Whereas single-exponential kinetics were observed for TC binding to the $40 \mathrm{~S}$ subunit in the presence of each mRNA (Fig. 5A; data not shown), TC binding in the absence of mRNA was biphasic (Fig. 6A). In Figure 6B, observed rate constants for the fast and slow phases seen without mRNA are plotted separately against $40 \mathrm{~S}$ subunit concentration. The fast phase is an order of magnitude more dependent on $40 \mathrm{~S}$ subunit concentration than the slow phase, yielding a rate constant of $4200 \mathrm{M}^{-1} \mathrm{~s}^{-1}$ versus

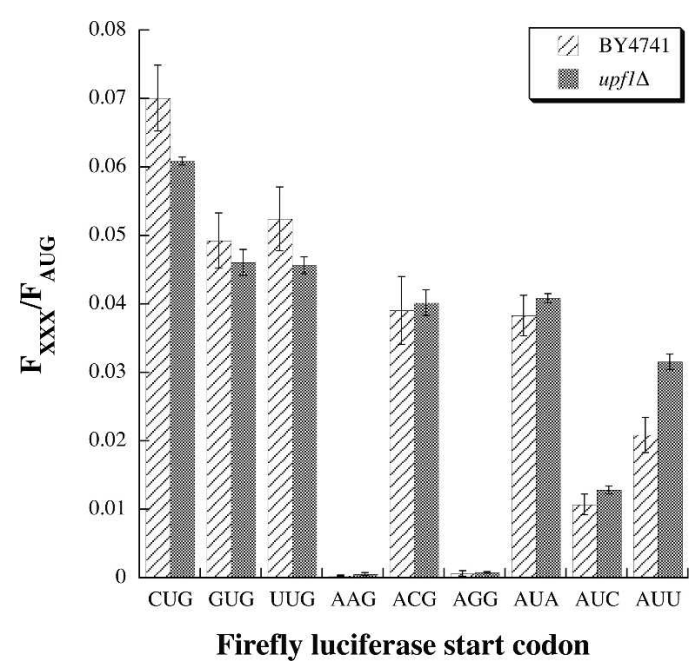

FIGURE 3. Single-base changes to the start codon affect the efficiency of translation of firefly luciferase in wild-type (BY4741) and nmddeficient $(u p f 1 \Delta)$ yeast. The $y$-axis is the activity of firefly luciferase translated using a near-cognate start codon $\left(F_{\mathrm{XXx}}\right)$ normalized to the activity of firefly luciferase with an AUG $\left(F_{\mathrm{AUG}}\right)$. Activities observed for AAG and AGG codons are equivalent to background levels. Values shown are averages of at least three measurements. Error bars are standard deviations. 


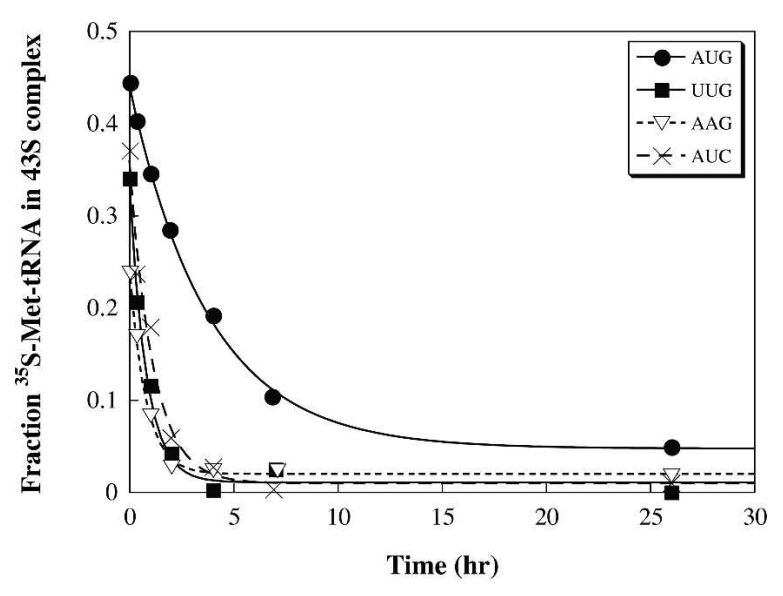

FIGURE 4. The rate of TC dissociation from 43S•mRNA complexes is not strongly codon-dependent. Values of $k_{\text {off }}$ were similar for a single-base change in each position of the start codon [mRNA(UUG) $(\boldsymbol{\bullet})$, mRNA(AAG) $(\nabla)$, and mRNA(AUC) $(\times)]$. Dissociation was three- to fourfold slower with an AUG codon $(\bullet)$. A representative curve is shown for each mRNA.

$500 \mathrm{M}^{-1} \mathrm{~s}^{-1}$ for the slow phase. The fast phase rate constant is similar to the rate constants observed with secondor third-position base changes in the start codon (Table 4), and likely represents the overall rate constant for TC binding to the $40 \mathrm{~S}$ subunit. The slow phase could be an additional rearrangement of the $43 \mathrm{~S}$ complex, only observed in the absence of mRNA, which pulls the equilibrium forward, resulting in more 43S formation (Johnson 1992).

These association and dissociation rate constants are consistent with the measured $K_{\mathrm{d}}$ values (Table 5), suggesting that the derived rate constants reflect the essential binding and dissociation events of $43 \mathrm{~S}$ complex formation in vitro.

\section{Compensatory single-base anticodon changes}

While changing bases in the start codon allows an investigation of the importance of base pairing, changing the anticodon of the initiator tRNA opens up a wider realm of base-pairing changes, and allows us to investigate further questions, such as sequence specificity. Is it sufficient to have any three base pairs between start codon and anticodon in initiation? Or is there something special about one or more of the actual bases in AUG that allows it specifically to trigger the events that lead to commitment of the complex? To address this question we employed nine initiator tRNAs with each possible single-base anticodon change (denoted by Met-tRNA $\mathrm{X}_{\mathrm{i}}^{\mathrm{XX}}$, where $\mathrm{XXX}$ is the anticodon read $5^{\prime}$ to $3^{\prime}$ ).

\section{Changes in anticodon can affect TC formation}

The altered tRNAs were charged with ${ }^{35} \mathrm{~S}$-Met (see Materials and Methods), and a filter-binding assay was used to measure binding of the altered Met-tRNAs to eIF2. A binding defect was observed for two altered tRNAs, Met-
$\mathrm{tRNA}_{\mathrm{i}}^{\mathrm{CAA}}$ and Met-tRNA $\mathrm{i}_{\mathrm{CG}}^{\mathrm{CG}}$. Thus even a single-base change in the anticodon of the initiator tRNA, a site distant from the acceptor end of the tRNA that interacts with eIF2 (Schmitt et al. 2002), can affect the binding of eIF2 to Met-tRNA $\mathrm{i}_{\mathrm{i}}$, suggesting long-range communication, as previously suggested by the influence of elements in the T-loop on the effects of base changes in the anticodon stem (Kapp et al. 2006). Given enough time (1 h), however, at the concentration of eIF2 used (200 nM), each tRNA was able to bind completely to eIF2•GDPNP (data not shown).

Anticodon changes affect the affinity of TC for the $40 S$ subunit

Next, $43 \mathrm{~S}$ complex formation experiments were performed with TC containing Met-tRNA $\mathrm{A}_{\mathrm{i}}^{\mathrm{XX}}$ as with wild-type MettRNA $_{i}$. Binding curves for one changed tRNA are shown as an example in Figure 7. A change in any position of the anticodon reduced the affinity of TC for the $40 \mathrm{~S}$ subunit in the presence of mRNA(AUG) (Table 6). In the case of tRNA ${ }_{i}^{\mathrm{GAU}}$ with mRNA(AUG), the apparent $K_{\mathrm{d}}(3.1 \pm$ $1.6 \mathrm{nM}$ ) may be affected by the fact that mRNA(AUG) contains an AUC codon very close to its $5^{\prime}$ end. (This AUC codon is present in each model mRNA, but is unlikely to affect wild-type tRNA binding because AUC is one of the weakest codons, with a $K_{\mathrm{d}}$ of $31 \mathrm{nM}$.) No anticodon position tolerated base substitutions better than the others, in contrast to our observations with changes to the codon in the mRNA. The presence of the compensatory mRNA, which should restore base pairing, restored binding to apparent wild-type affinity in all cases (Table 6). We also observed that changes to the anticodon affected binding independently of the presence of a codon. Even in the absence of mRNA, binding of TC containing anticodon changes was in several cases weaker than binding of TC containing wild-type Met-tRNA $A_{i}$ (e.g., tRNA ${ }_{i}^{\mathrm{CGU}}$, $\mathrm{tRNA}_{i}^{\mathrm{GAU}}$ ) (Table 6). This suggests some recognition of the anticodon end of the tRNA by the complex, either directly or because of changes in the overall tRNA structure, independent of codon/anticodon base pairing. This observation is consistent with the unique conformation of the anticodon loop of initiator tRNAs, which could be perturbed by base changes in the anticodon (Barraud et al. 2008; Woo et al. 1980).

TABLE 3. Rate constants for dissociation of TC from $43 \mathrm{~S}$ complex

\begin{tabular}{lc}
\hline Codon & $\begin{array}{c}k_{\text {off }} \\
\left(\mathrm{h}^{-1}\right)\end{array}$ \\
\hline AUG & $0.20 \pm 0.06$ \\
UUG & $0.82 \pm 0.39$ \\
AAG & $0.82 \pm 0.25$ \\
AUC & $0.67 \pm 0.33$ \\
No mRNA & $0.92 \pm 0.22$ \\
\hline
\end{tabular}

Values are the averages of at least four independent experiments. Errors are average deviations. 
A

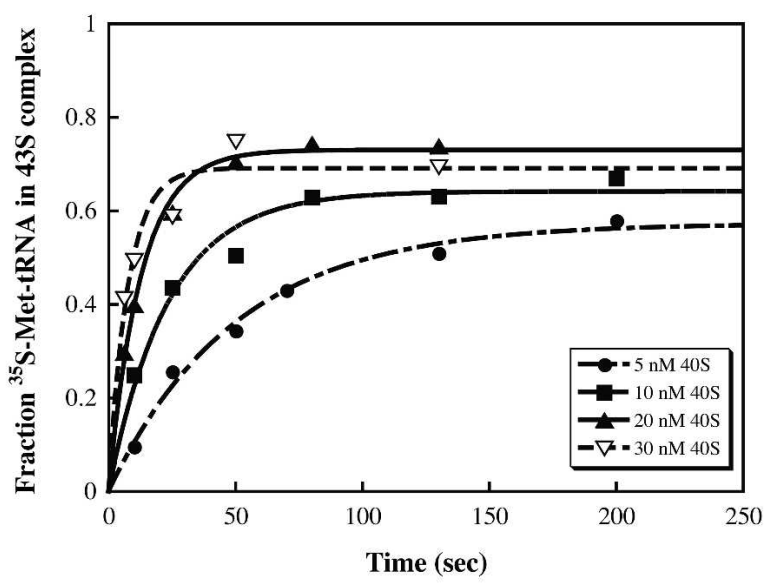

C

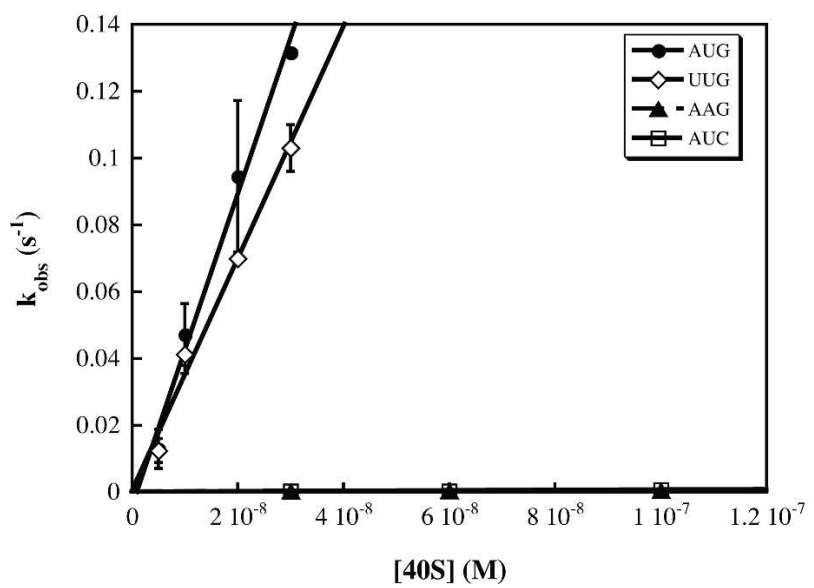

B

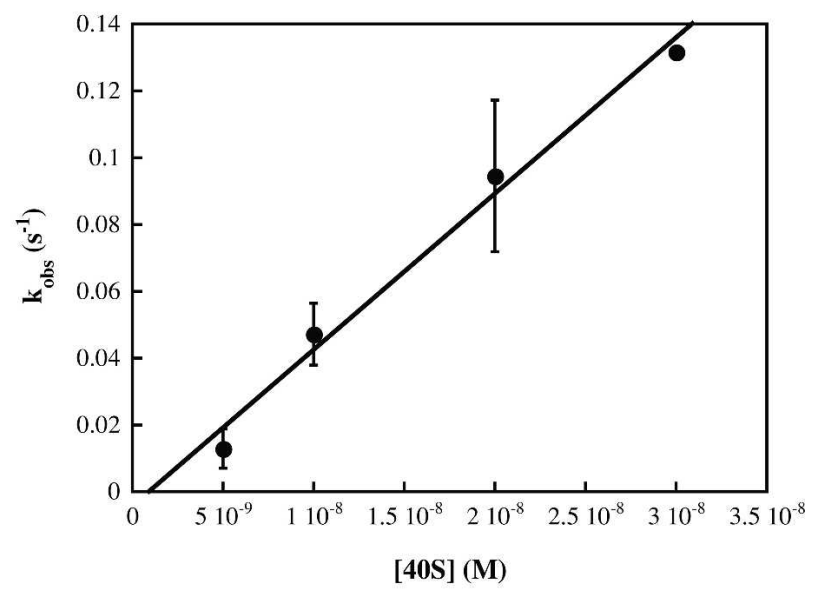

FIGURE 5. The rate constant for TC binding to the $40 \mathrm{~S}$ subunit is highly dependent on the start codon present in the mRNA. The kinetics of TC formation at several concentrations of $40 \mathrm{~S}$ subunits were measured and fit with a single exponential equation (see Materials and Methods) to obtain observed rate constants. A representative experiment with mRNA(AUG) is shown $(A)$. Observed rate constants were plotted against the concentration of $40 \mathrm{~S}$ subunits and fit linearly to obtain the second-order rate constant for complex formation; these data are shown for mRNA(AUG) in $(B)$. The $k_{\text {on }}$ is the slope of the line. The first three points are averages of three independent experiments, and the last point (30 $\mathrm{nM} 40 \mathrm{~S})$ is an average of two independent experiments. The $\mathrm{x}$-intercept, which is very near zero, indicates that the rate constant for dissociation is quite small, consistent with our measurements. The data for one base change in each position are shown in $(C)$ [UUG $(\diamond)$, AAG $(\boldsymbol{\Delta})$, and AUC $(\square)$ ]. The $k_{\text {on }}$ was significantly higher for mRNA(AUG) $(\bullet)$ and mRNA(UUG) [as well as mRNA(GUG), not shown] than for other single-base changes. Each point shown is the average of at least two independent experiments, except for the mRNA(AUC) points and the $20 \mathrm{nM}$ point in the mRNA(UUG) line, which came from single experiments. Error bars are average deviations.

We also examined TC binding to the $40 \mathrm{~S}$ subunit in the case of a potential G-U wobble pairing between anticodon and start codon in each position. For example, wild-type $\mathrm{tRNA}_{\mathrm{i}}+$ mRNA(GUG) could potentially form a G-U wobble pairing at the first position, as might $\mathrm{tRNA}_{\mathrm{i}}^{\mathrm{CAG}}+$ mRNA(UUG). For each position of the start codon, two such codon/anticodon combinations could produce a $\mathrm{G}-\mathrm{U}$ wobble, one in each direction ( $G$ in the anticodon or $G$ in the start codon). We observed that in the first and second positions of the start codon, both possible G-U wobble pairings resulted in relatively tight binding, though an endpoint difference was seen between the two pairings for each position (Table 7). In the third position of the start codon, however, the direction of the G-U wobble strongly affected the affinity of TC for the 40S subunit, with a pairing in one direction ( $U$ in the codon, $G$ in the anticodon) resulting in tight binding, but a pairing in the other ( $\mathrm{G}$ in the codon, $\mathrm{U}$ in the anticodon) resulting in weak binding. This could indicate that the shape of the $\mathrm{P}$ site constrains the possible base pairs between codon and anticodon. Indeed, in the $2.8 \AA$ structure of the bacterial $70 \mathrm{~S}$ ribosome with $\mathrm{P}$ site tRNA and mRNA (Selmer et al. 2006) the $P$ site is densely packed, more so than the A site. It appears most spatially constrained by ribosomal RNA 
TABLE 4. Rate constants for TC binding to the $40 \mathrm{~S}$ subunit

\begin{tabular}{lc}
\hline Codon & $\begin{array}{c}k_{\text {on }} \\
\left(\mathrm{M}^{-1} \mathrm{~s}^{-1}\right)\end{array}$ \\
\hline AUG & $5.6 \times 10^{6} \pm 1.2 \times 10^{6}$ \\
CUG & $48,000 \pm 200$ \\
GUG & $4.9 \times 10^{6} \pm 1.0 \times 10^{6}$ \\
UUG & $3.5 \times 10^{6} \pm 3.0 \times 10^{5}$ \\
AAG & $3400 \pm 800$ \\
ACG & $3300 \pm 1300$ \\
AGG & $3400 \pm 2300$ \\
AUA & $5500 \pm 100$ \\
AUC & $6000 \pm 200$ \\
AUU & $4700 \pm 2000$ \\
No mRNA & $4200 \pm 600$ \\
\hline
\end{tabular}

Values are the averages of at least two independent experiments. Errors are average deviations.

near the third position of the codon, with 16S rRNA bases C1400 and G966 contacting the third position base pair. This constraint could explain the directional effects of $\mathrm{G}-\mathrm{U}$ wobbles in the third position, although the extent of similarity of the P site of the ribosome between eukaryotes and bacteria, as well as the effects of initiation factors on the structure of the P site, are not fully known.

\section{A matching codon/anticodon pair restores the rate of TC binding to the $40 S$ subunit}

The rate of TC binding to the $40 \mathrm{~S}$ subunit was measured with Met-tRNA ${ }_{i}^{\text {CAG }}$ and mRNA(CUG) (Fig. 8). We observed that this changed, matching pair restored the rate constant for association [from 48,000 $\pm 200 \mathrm{M}^{-1} \mathrm{~s}^{-1}$ for wild-type Met-tRNA ${ }_{i}+$ mRNA$\left._{(\mathrm{CUG})}\right]$ to the wild-type value $[5.0 \times$
$10^{6} \pm 1.0 \times 10^{6} \mathrm{M}^{-1} \mathrm{~s}^{-1}$ for Met-tRNA $\left.{ }_{\mathrm{i}}^{\mathrm{CAG}}+\mathrm{mRNA}^{\mathrm{CUG}}\right)$ versus $5.6 \times 10^{6} \pm 1.2 \times 10^{6} \mathrm{M}^{-1} \mathrm{~s}^{-1}$ for the wild-type interaction, Met-tRNA + mRNA(AUG)]. As the 40S•mRNA (CUG) complex is the same before TC binding whether TC contains Met-tRNA or Met-tRNA $_{i}{ }^{\mathrm{CAG}}$, yet a huge difference in rate constant is observed in these two cases, this result makes it unlikely that the strongly codon-dependent differences in $k_{\text {on }}$ observed with wild-type Met-tRNA $A_{i}$ result from a codon-dependent conformational difference in the ribosome prior to TC binding. Thus, in the association experiment we are likely observing an additional step beyond initial diffusion-controlled binding of TC to 40S, presumably a step involving base pairing between codon and anticodon that locks the $43 \mathrm{~S}$ complex into a stable state. This latter step apparently is dramatically accelerated by the ability to form three Watson-Crick base pairs over two.

\section{DISCUSSION}

\section{Start codon changes affect initiation in vivo and in vitro}

The relevance of studying the effects of base changes in the start codon is clear, since many near-cognate codons are present in mRNA. As a starting point to understanding how pairing between the start codon and the anticodon of the initiator tRNA triggers downstream events in the initiation process, we examined the effects of start codon changes on binding of both mRNA and TC to the 40S subunit.

The affinity of mRNA for the $40 \mathrm{~S}$ subunit appears dependent to some extent on mRNA sequence, independent of the presence of $\mathrm{tRNA}_{i}$ in the complex. The effect of codons on the affinity of mRNA for the $40 \mathrm{~S}$ subunit does
A

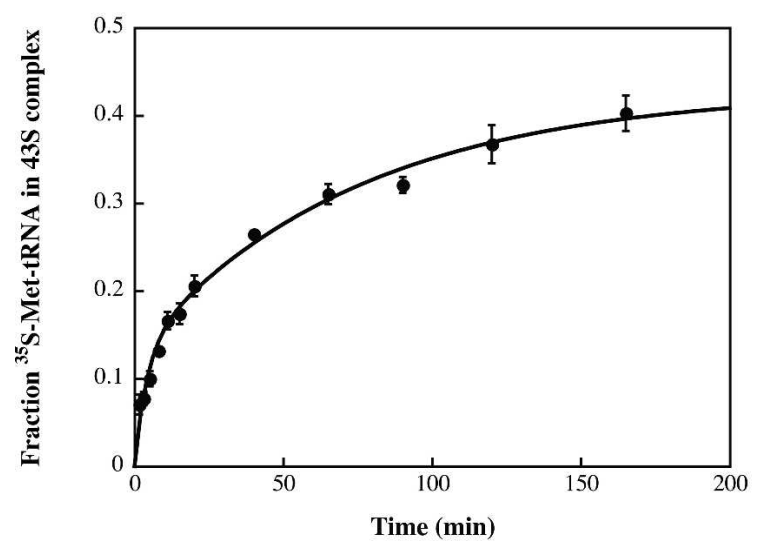

B

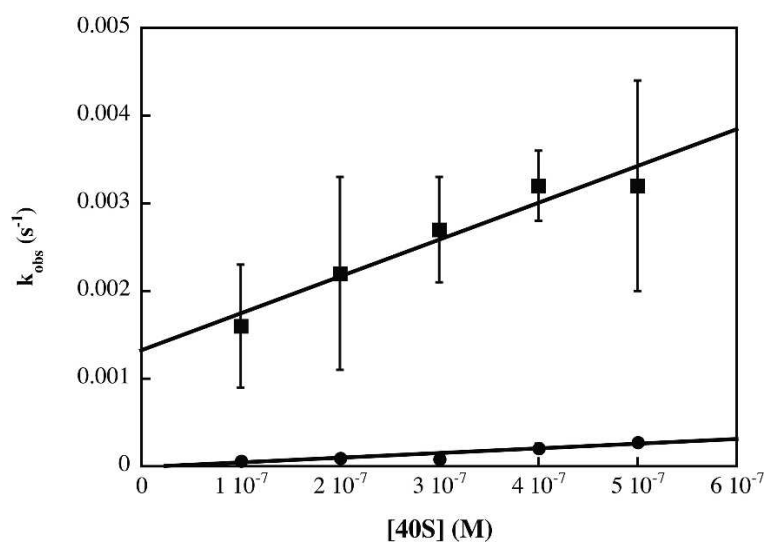

FIGURE 6. In the absence of mRNA, TC binds to the $40 \mathrm{~S}$ subunit with biphasic kinetics. The curve in $(A)$ is the average of two experiments carried out at $400 \mathrm{nM} 40 \mathrm{~S}$ subunits. In $(B)$, the observed rate constants for the fast phase $(\bullet)$ and the slow phase $(\bullet)$ are shown plotted against the concentration of $40 \mathrm{~S}$ subunits at which they were obtained. The fast phase yields a slope of $4200 \mathrm{M}^{-1} \mathrm{~s}^{-1}$ and the slow phase a slope of 500 $\mathrm{M}^{-1} \mathrm{~s}^{-1}$. The observed rate constants for the fast phase are the averages of at least three experiments and were previously published in Passmore et al. (2007). The observed rate constants for the slow phase are from one, two, or three experiments. Error bars are average deviations. 
TABLE 5. $k_{\text {on }}, k_{\text {off }}$ values are consistent with $K_{\mathrm{d}}$ values

\begin{tabular}{lcc}
\hline Codon & $\begin{array}{c}\text { Measured } K_{\mathrm{d}} \\
(\mathrm{nM})\end{array}$ & $\begin{array}{c}k_{\text {off }} / k_{\text {on }} \\
(\mathrm{nM})\end{array}$ \\
\hline AUG & $<1$ & 0.01 \\
UUG & $<1$ & 0.07 \\
AAG & $67 \pm 17$ & 70 \\
AUC & $31 \pm 8.8$ & 30 \\
No mRNA & $67 \pm 12$ & 60 \\
\hline
\end{tabular}

not mirror the effect of codons on TC binding except in gross terms [e.g., mRNA(CUC) is worse than any single base change]. These data suggest that there is no specific interaction between the ribosome and an AUG codon in singlestranded mRNA; however, these data do not address whether such an interaction may exist in the context of a duplex formed between codon and anticodon in the P site.

Ranking codons by the $K_{\mathrm{d}}$ values for TC binding to the $40 \mathrm{~S}$ subunit, the hierarchy is similar to that observed in vivo in S. cerevisiae using a luciferase reporter assay. In vivo, we observed the hierarchy CUG > UUG/GUG > ACG/AUA $>$ AUU $>$ AUC $\gg$ AGG/AAG. In vitro, the order was UUG/GUG/CUG > AGG/AUA/AUU > ACG/ AUC $>$ AAG. In each hierarchy, first position changes are least detrimental, and second position changes are generally worse than third position changes. This ranking differs from previously published rankings of start codon changes, which also differ from one another. In a study by Peabody (1989) observing translation of dihydrofolate reductase in wheat germ and rabbit reticulocyte lysates and in cultured monkey cells, ACG and CUG were best, followed by changes in the third position, and UUG, GUG, AAG, and AGG were worst. Work by Donahue and Cigan measured initiation of translation on a HIS4-lacZ fusion construct in $S$. cerevisiae and saw that AUA was the best near-cognate codon, followed by AUU and GUG, and middle position changes were worst, ACG being the very worst (Donahue and Cigan 1988). A study measuring translation from nearcognate codons on a CYC7-lacZ fusion in yeast (Clements et al. 1988) observed that GUG, ACG, AUU, and UUG were similar, and slightly better than AUA and CUG, which were much better than AUC, AGG, and AAG, although the level of translation from each nearcognate codon was $<1 \%$ of the level observed with an AUG codon. The last hierarchy is similar to the one we observed in vivo. Valásek et al. exam- ined start codon changes to UUG or AUU using a HIS4lacZ fusion in yeast, and the observed effects were quite similar in magnitude to the effects seen for those codons in our in vivo assay (Valásek et al. 2004). It is not clear why the orders determined in previous work differ from one another, or from our in vivo study. However, the point of consensus from these studies appears to be that changes in the middle position are worse overall than changes in the first or third positions, which agrees with our results.

Some differences do exist between the in vitro and in vivo rankings reported here. In particular, the CUG codon was used more readily as an initiation codon in vivo than would have been anticipated from the in vitro data. Likewise, utilization of AGG was lower in vivo than would have been predicted by the in vitro analysis. Our unpublished results indicate that the yeast $5^{\prime}$-consensus sequence (AAAA before the start codon), which was present in the in vivo reporter constructs used here but absent in the mRNAs used in the in vitro binding studies, affects translation of the firefly luciferase mRNA. It is possible that part of the disparity between the in vivo and in vitro results arises from effects of this consensus sequence. In addition, the step we have probed here in vitro, TC binding to the 40 S subunit, clearly lacks the information contained in the rest of the initiation process (i.e., events taking place after stable codon/anticodon pairing), which could be responsible for the differences between the orders observed in vivo and in vitro. Modifications of the initiator tRNA could also play a role. However, the fact that the hierarchy seen in vitro is similar to that observed in vivo supports the relevance of the TC binding data to the study of start codon recognition.

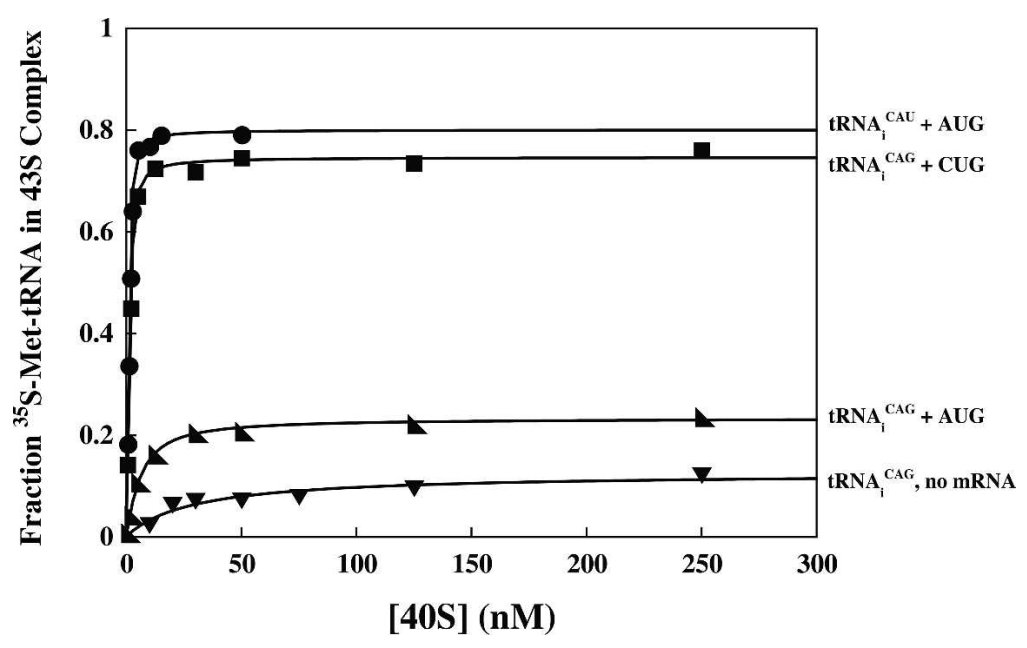

FIGURE 7. TC containing tRNA with a single-base anticodon change (Met-tRNA ${ }_{i}^{\text {CAG }}$ ) bound more weakly and with a lower final fraction bound than TC containing wild-type tRNA, both in the absence of mRNA ( $\mathbf{v})$ and with mRNA(AUG) (-). With mRNA(CUG) (-), which contains the matching codon, binding is restored. Other changed tRNAs behaved similarly (Table 6). The binding curve for the wild-type Met-tRNA $A_{i}+m R N A(A U G)$ interaction $(\bullet)$ is shown for reference. Each curve is the average of at least two independent experiments. 
TABLE 6. Affinity of TC containing anticodon changes for the $40 \mathrm{~S}$ subunit

\begin{tabular}{|c|c|c|c|c|c|c|}
\hline \multirow[b]{2}{*}{ Anticodon } & \multicolumn{2}{|c|}{ AUG } & \multicolumn{2}{|c|}{ Matching mRNA } & \multicolumn{2}{|c|}{ No mRNA } \\
\hline & $\begin{array}{l}\text { Apparent } K_{\mathrm{d}} \\
(\mathrm{nM})\end{array}$ & $\begin{array}{c}\text { Endpoint } \\
\text { (fraction bound) }\end{array}$ & $\begin{array}{l}\text { Apparent } K_{\mathrm{d}} \\
(\mathrm{nM})\end{array}$ & $\begin{array}{c}\text { Endpoint } \\
\text { (fraction bound) }\end{array}$ & $\begin{array}{l}\text { Apparent } K_{\mathrm{d}} \\
(\mathrm{nM})\end{array}$ & $\begin{array}{c}\text { Endpoint } \\
\text { (fraction bound) }\end{array}$ \\
\hline CAU & $<1$ & $0.80 \pm 0.03$ & - & - & $67 \pm 12$ & $0.50 \pm 0.05$ \\
\hline CAG & $6.7 \pm 1.6$ & $0.26 \pm 0.03$ & $<1$ & $0.70 \pm 0.07$ & $48 \pm 17^{*}$ & $0.13 \pm 0.02 *$ \\
\hline CAC & $5.3 \pm 1.3$ & $0.29 \pm 0.01$ & $<1$ & $0.74 \pm 0.03$ & $89 \pm 30$ & $0.78 \pm 0.12$ \\
\hline CAA & $43 \pm 12$ & $0.36 \pm 0.24$ & $<1$ & $0.57 \pm 0.10$ & $111 \pm 64$ & $0.18 \pm 0.01$ \\
\hline CUU & $32 \pm 6.9$ & $0.42 \pm 0.26$ & $<1$ & $0.79 \pm 0.07$ & $62 \pm 22$ & $0.31 \pm 0.23$ \\
\hline CGU & $<3$ & $0.54 \pm 0.01$ & $<1$ & $0.79 \pm 0.01$ & $172 \pm 38$ & $0.71 \pm 0.12$ \\
\hline $\mathrm{CCU}$ & $15 \pm 6.0$ & $0.47 \pm 0.06$ & $<1$ & $0.67 \pm 0.13$ & $49 \pm 11$ & $0.49 \pm 0.0$ \\
\hline UAU & $38 \pm 11$ & $0.27 \pm 0.07$ & $<1$ & $0.65 \pm 0.03$ & $80 \pm 9$ & $0.13 \pm 0.0$ \\
\hline GAU & $3.1 \pm 1.6^{\mathrm{a}}$ & $0.46 \pm 0.03^{a}$ & $<1$ & $0.70 \pm 0.07$ & $168 \pm 8$ & $0.31 \pm 0.1$ \\
\hline AAU & $3.8 \pm 0.9^{*}$ & $0.11 \pm 0.01 *$ & $<2$ & $0.59 \pm 0.09$ & $149 \pm 52$ & $0.35 \pm 0.16$ \\
\hline
\end{tabular}

Values are the averages of at least two independent experiments. Errors are average deviations. For values marked with an asterisk $(*)$, data were averaged and the values and errors reported are from the fit of the averaged data. When averaging $K_{\mathrm{d}}{ }^{\prime} \mathrm{s}$ that included curve fits that were undefinably tight $(<1 \mathrm{nM})$, the resulting average $K_{\mathrm{d}}$ represents an upper bound and is reported as such (e.g., in this case an average $K_{\mathrm{d}}$ determined as $3 \mathrm{nM}$ is denoted as " $<3 \mathrm{nM}^{\prime \prime}$ ).

${ }^{a}$ The possibility exists that tRNA ${ }_{i}^{G A U}$ may base pair with the AUC codon near the $5^{\prime}$ end of mRNA(AUG); the apparent affinity shown here may reflect this interaction.

\section{Compensatory anticodon changes suppress effects of start codon changes}

We also examined changes to the anticodon of Met-tRNA $A_{i}$. Although initiator tRNAs containing anticodon changes are unlikely to be found in vivo, their use in this investigation sheds light on both the importance of base pairing for the response of the $43 \mathrm{~S}$ complex to start codon recognition and structural constraints that may exist in the $\mathrm{P}$ site of the eukaryotic ribosome. Making changes to the Met-tRNA anticodon allowed an investigation of sequence dependence by using matching codon/anticodon pairs.

Evidence for the importance of a matching codon/ anticodon pair for initiating translation in vivo comes from several previous studies. In Cigan et al. (1988) an $S$. cerevisiae strain bearing an initiator tRNA with the anticodon changed to $5^{\prime}$-CCU-3' was able to translate His4 by initiating at an AGG codon. Similarly, in Drabkin and RajBhandary (1998) production of chloramphenicol acetyltransferase in mammalian COS1 cells proceeded from an AGG or GUC codon, using human initiator tRNAs with the anticodon changed to CCU or GAC, respectively (in the case of the GAC anticodon, the tRNA was aminoacylated with valine instead of methionine). In vitro, using a mammalian reconstituted system, formation of a preinitiation complex was observed with a human initiator tRNA with a CCU anticodon and an mRNA containing an AGG codon (Lomakin et al. 2006). Consistent with these results, we observed that start codon/anticodon pairs bearing compensatory single-base changes allowed tight binding of TC to the 40S subunit, and in at least one case restored the $k_{\text {on }}$ value for TC binding to the $40 \mathrm{~S}$ subunit. Clearly, base pairing is central, and the ability to allow for formation of a stable 43S•mRNA complex is not specific to the AUG sequence.

Several observations, however, indicate that TC binding is not dictated exclusively by the expected stability of the start codon/anticodon duplex. For example, mRNA(UUG) removes an $\mathrm{A}-\mathrm{U}$ base pair relative to mRNA(AUG), but results in a $k_{\text {on }}$ value indistinguishable from the $k_{\text {on }}$ value with $\mathrm{mRNA}(\mathrm{AUG})$. In addition, mRNA(CUG) removes the same A-U base pair as mRNA(UUG), but results in a 100fold smaller $k_{\text {on }}$ value. Also, while the U-U mismatch in the first position created by mRNA(UUG) results in a $K_{\mathrm{d}}$ value of $<1 \mathrm{nM}$, a $\mathrm{U}-\mathrm{U}$ mismatch in the second position results in a $K_{\mathrm{d}}$ of $32 \mathrm{nM}$. In Kierzek et al. (1999) it was shown that

TABLE 7. Orientation of potential G-U wobble base pairs affects binding of TC to the $40 S$ subunit

\begin{tabular}{lcccc}
\hline $\begin{array}{l}\text { Position } \\
\text { in codon }\end{array}$ & Codon & Anticodon & $\begin{array}{c}\text { Apparent } K_{\mathrm{d}} \\
(\mathrm{nM})\end{array}$ & $\begin{array}{c}\text { Endpoint } \\
\text { (fraction bound) }\end{array}$ \\
\hline 1 & $\mathrm{G}$ & $\mathrm{U}$ & $<1$ & $0.67 \pm 0.01$ \\
& $\mathrm{U}$ & $\mathrm{G}$ & $<4$ & $0.37 \pm 0.03$ \\
2 & $\mathrm{G}$ & $\mathrm{U}$ & $<2$ & $0.27 \pm 0.07$ \\
& $\mathrm{U}$ & $\mathrm{G}$ & $<3$ & $0.54 \pm 0.01$ \\
3 & $\mathrm{G}$ & $\mathrm{U}$ & $38 \pm 11$ & $0.27 \pm 0.07$ \\
& $\mathrm{U}$ & $\mathrm{G}$ & $<1^{\mathrm{a}}$ & $0.68 \pm 0.0^{\mathrm{a}}$ \\
\hline
\end{tabular}

Values are the averages of at least two independent experiments. Errors are average deviations. When averaging data that included curve fits that were undefinably tight $(<1 \mathrm{nM})$, the resulting average $K_{\mathrm{d}}$ represents an upper bound and is reported as such.

${ }^{a}$ It is possible that for tRNA $\mathrm{G}_{i}+$ RUNA(AUU), the presence of the AUC codon near the $5^{\prime}$ end of mRNA(AUU) might affect binding, although the apparent affinity in this case is tighter than that measured for tRNA $\mathrm{GAU}_{i}+\mathrm{mRNA}(\mathrm{AUG})(3.1 \pm 1.6 \mathrm{nM})$, which also contains the $5^{\prime} \mathrm{AUC}$, indicating that the AUU codon is recognized. 


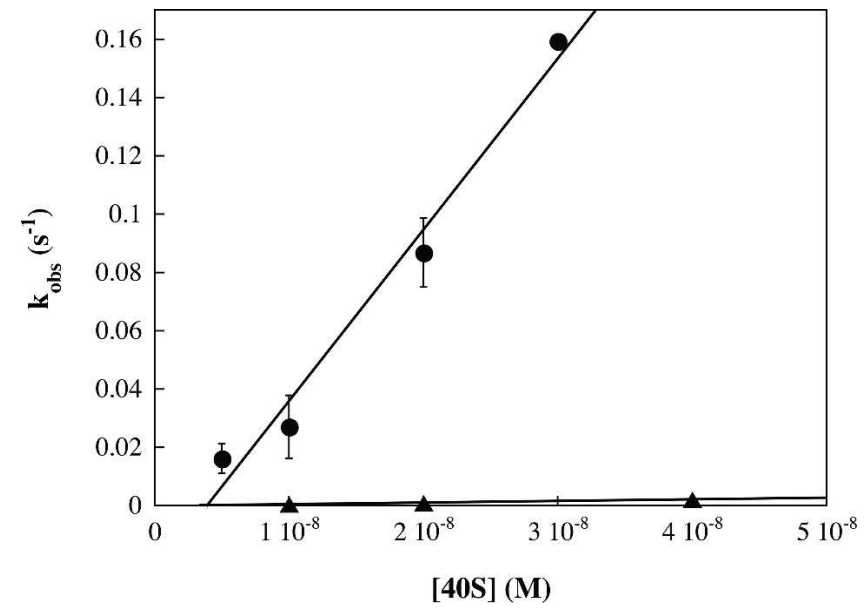

FIGURE 8. A matching start codon/anticodon pair restores the rate constant for TC binding to the $40 \mathrm{~S}$ subunit. Observed rate constants for TC binding the $40 \mathrm{~S}$ subunit are shown plotted against the $40 \mathrm{~S}$ subunit concentrations at which they were determined; the slope of each line is the rate constant for TC binding to the $40 \mathrm{~S}$ subunit. Both experiments were done in the presence of $\mathrm{mRNA}(\mathrm{CUG})$. The $k_{\text {on }}$ is 100 -fold higher with the matching tRNA, Met-tRNA ${ }_{\mathrm{i}}{ }^{\mathrm{CAG}}\left(\bullet ; 5.0 \times 10^{6} \pm\right.$ $\left.1.0 \times 10^{6} \mathrm{M}^{-1} \mathrm{~s}^{-1}\right)$, than with wild-type Met-tRNA $(\mathbf{\Lambda} ; 48,000 \pm 200$ $\left.\mathrm{M}^{-1} \mathrm{~s}^{-1}\right)$; the compensatory anticodon change restores the $k_{\mathrm{on}}$ with mRNA(CUG) to the rate constant for the wild-type Met-tRNA $A_{i}+$ mRNA(AUG) pair $\left(5.6 \times 10^{6} \pm 1.2 \times 10^{6} \mathrm{M}^{-1} \mathrm{~s}^{-1}\right.$; compare to Fig. $5 \mathrm{~B})$. The first three points in each line are the average of two independent experiments; the last point (for the highest $40 \mathrm{~S}$ subunit concentration) in each line is from one experiment. Error bars are average deviations.

the stability of a seven base-pair duplex increased when a $\mathrm{U}-\mathrm{U}$ mismatch was moved closer to the edge of the helix, which could account for our observation. The same effect, however, was demonstrated for an A-A mismatch, which we observed to yield much more similar $K_{\mathrm{d}}$ values in both the first and second positions (43 and $67 \mathrm{nM}$ in the first and second position, respectively). The fact that, in general, disruption of a central base pair in a helix is worse than disruption of a terminal base pair could contribute to position-dependent differences in the effect of a mismatch. However, a $\mathrm{G}-\mathrm{U}$ wobble pairing also results in similar $K_{\mathrm{d}}$ values in both the first and second positions, and an A-G mismatch yields $K_{\mathrm{d}}$ values that are similar (7, 9, and $4 \mathrm{nM}$ ) in all three positions. The similarity of the $K_{\mathrm{d}}$ values for the A-G mismatch in the first and third positions ( 7 and $4 \mathrm{nM}$, respectively) is also surprising; a more detrimental effect might be anticipated in the third position than in the first position, since neither base change is in the center of the helix, and the third position disrupts a $\mathrm{G}-\mathrm{C}$ base pair, which is energetically more costly than disrupting an $\mathrm{A}-\mathrm{U}$ pair. It is possible that some or all of these observations could result from the existence of structural constraints imposed by the $\mathrm{P}$ site, or interactions of anticodon or start codon bases with the $\mathrm{P}$ site that affect the stability of the duplex. These observations are also consistent with the idea that a more complex series of events may occur upon start codon/anticodon duplex formation, altering the stability of TC binding.

Strong evidence that base pairing is not the exclusive determinant of sequence-dependent changes in complex stability comes from the large differences in $k_{\text {on }}$ values for TC binding to the $40 \mathrm{~S}$ subunit and the small differences in $k_{\text {off }}$ values for TC dissociation from 43S•mRNA complex. The data are surprising, given that the opposite is seen in experiments monitoring RNA duplex formation and dissociation with or without base-pairing mismatches (Yoon et al. 1976; Wang et al. 1995). In those experiments, the rate constants for duplex dissociation depend on base pairing strength while the rate constants for association of the strands do not; stability of the duplex is governed by effects on the dissociation rate constant instead of the association rate constant. This indicates that the codon/anticodondependent interaction between TC and the 40S•eIF1• eIF1A $\bullet$ mRA complex must be governed by more than simply the stability of the start codon/anticodon duplex; while this interaction is key, it does not exclusively determine the state of the complex. We propose that base pairing induces a conformational change that commits the complex to a more stable state.

\section{Induced-fit model}

The observed change in stability must occur after the collision of TC with the 40S subunit. The 40S subunit bound to mRNA(CUG) exists in the same conformation before it binds to TC regardless of whether the TC contains wild-type Met-tRNA $\mathrm{i}_{\mathrm{i}}$ or Met-tRNA $\mathrm{CAG}_{\mathrm{C}}$. Thus, a codondependent conformation of the $40 \mathrm{~S}$ subunit cannot explain the dramatic difference in binding rate constants between the two cases. It appears much more likely that the $>100$ fold increase in rate constant for binding of TC containing Met-tRNA ${ }_{i}^{C A G}$ versus wild-type $\mathrm{TC}$ in the presence of mRNA(CUG) results from an event that occurs after the initial diffusion-controlled encounter of TC with the $40 \mathrm{~S}$ subunit. One possibility is an induced fit involving codon/ anticodon duplex formation such that the right complex (with matching base pairing) commits more rapidly than a wrong complex.

The model suggested by our data is shown in Fig. 9. Using this model, we fit the data for the rates of binding of $\mathrm{TC}$ to the $40 \mathrm{~S}$ complex with either mRNA(AUG) or the near-cognate mRNA(AAG) using the program Berkeley Madonna (Macey et al. 2000) to estimate the rate constants for conversion of the encounter complex to the more stable complex. In both cases, we assumed a second-order rate constant for the initial encounter of TC and 40S complex of $10^{7} \mathrm{M}^{-1} \mathrm{~s}^{-1}$ and a reverse rate constant for this step of $1 \mathrm{~s}^{-1}$, and used the measured rate constants for TC dissociation as the reverse rate constants for the second step. Fitting the kinetic data for TC binding to the 40S subunit in the presence of mRNA(AAG) yielded a rate constant of 
A

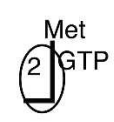

B

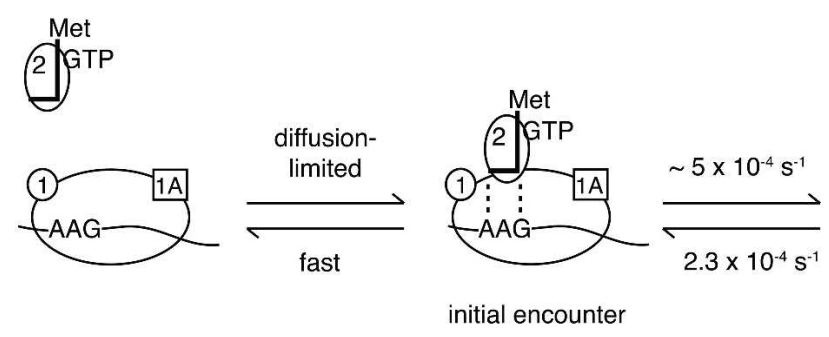

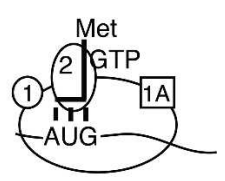

stable complex

of the AUG codon. Our proposal that following the initial encounter of TC with the $40 \mathrm{~S}$ subunit there is a conformational rearrangement, the rate of which is highly dependent on formation of three base pairs between codon and anticodon, is consistent with previous data suggesting a transition from an open complex to a stable closed complex upon recognition of the start codon (Pestova and Kolupaeva 2002; Maag et al. 2006; Fekete et al. 2007). We observed that after the initial encounter of TC with 40S•eIF1・eIF1A•mRNA, the complex locks rapidly into a stable state if an AUG, UUG, or GUG codon is present (or, for the one case tested, if an altered but matching start codon/ anticodon pair is present). If another near-cognate codon is present, the complex moves much more slowly into the stable state, and a significant fraction of it is actually in the unstable state at equilibrium. The stable state we observe could be related to the "closed," scanning-incompetent state of the preinitiation complex proposed in Pestova and $\sim 5 \times 10^{-4} \mathrm{~s}^{-1}$ for the first-order conversion of the initial encounter complex to the more stable state. The equilibrium constant for conversion resulting from this forward rate constant is only $\sim 2$, which could explain why a lower endpoint is observed for the near-cognate codons that have lower apparent second-order rate constants for TC binding. Similar fits indicated that the rate constant for the same step in the case of mRNA(AUG) was about $10^{4}$ times higher $\left(\sim 1 \mathrm{~s}^{-1}\right)$, yielding an equilibrium constant for conversion of $\sim 2 \times 10^{4}$, strongly in favor of the stable complex.

In the absence of mRNA, the kinetics of TC binding to the $40 \mathrm{~S}$ subunit follows a double exponential curve. No evidence of double-exponential character, however, was seen in the presence of mRNA(AUG) or mRNAs with nearcognate codons. An intermediate complex may occur in the absence of mRNA, the formation of which is precluded by prebinding of mRNA to the $40 \mathrm{~S}$ subunit. The very shallow dependence on $40 \mathrm{~S}$ subunit concentration of the second phase strongly suggests that this second step is limited by a first-order event, likely a conformational rearrangement of the complex (Johnson 1992). In support of this, we were able to reproduce the data in Figure $6 \mathrm{~B}$ very closely by simulating this two-step process using Berkeley Madonna and the experimentally derived rate constants (data not shown).

Our observations could bear relevance to scanning, as the events observed here may give insight into the capture

Kolupaeva (2002) and observed by Maag et al. (2006) and Fekete et al. (2007). The observation made using Berkeley Madonna that given our model, the rate constant for conversion from the initial encounter complex to the more stable state is $10^{4}$-fold greater with AUG versus a nearcognate codon is consistent with what might be expected for the open-closed conformational conversion. In the current model for translation initiation, the $43 \mathrm{~S}$ complex forms and then is loaded onto the mRNA, a situation different from the one examined here. Our data, however, give insight into the events that take place when the $43 \mathrm{~S}$ complex encounters a start codon, suggesting that codon/ anticodon pairing induces a conformational rearrangement in the complex, resulting in a more stable state.

Furthermore, in certain biological situations, a codondependent effect on the rate of TC binding to $40 \mathrm{~S}$ subunits already bound to mRNA is relevant. For example, the mRNA for the transcription factor Gcn4 is translated under amino acid starvation conditions, when the availability of TC is low enough to allow the $40 \mathrm{~S}$ subunit to bypass several regulatory open reading frames upstream of the GCN4 ORF and initiate at the GCN4 start codon. In this case, the rate of TC binding to 40S•mRNA is critical for determining whether the $40 \mathrm{~S}$ complex reaches the downstream GCN4 start codon (Hinnebusch 2005). Our data indicate that the rate at which TC binds stably may be dependent upon the location in the message at which the $40 \mathrm{~S}$ subunit is bound, with the rate dramatically influenced 
by the codon in the $\mathrm{P}$ site. Perhaps other sequence elements, or the frequency of codons in the mRNA, help to tune the rate of binding so that the system is properly controlled.

The mechanism by which the 43S•mRNA complex senses the formation of a three base-pair start codon/anticodon helix, and how that causes the conformational change that results in a more stable complex, remains to be determined. Perhaps the three-base-pair duplex is directly recognized by the $\mathrm{P}$ site; alternatively, some combination of the Met$\mathrm{tRNA}_{\mathrm{i}}$ and/or initiation factors could sense duplex formation and transmit the signal.

Clearly, determinants of start codon selection exist beyond the stability of the $43 \mathrm{~S}$ complex with respect to TC as we have measured it, since the $K_{\mathrm{d}}$ and $k_{\text {on }}$ values for GUG and UUG codons are quite similar to the values seen with AUG, whereas these near-cognate codons do not function as well as AUG in vivo. Some other means must help the complex to discriminate against these codons; for instance, possibly the effects of tRNA modifications on the $k_{\text {off }}$ value, as noted above. Other steps and eIFs contribute to achieving recognition of the start codon. The codon dependence of several subsequent steps in initiation, such as release of eIF1 from the $43 \mathrm{~S}$ complex and phosphate release from eIF2 $\bullet \mathrm{GDP} \bullet \mathrm{P}_{\mathrm{i}}$, has been investigated. In Maag et al. (2005) and Cheung et al. (2007), FRET and in vivo experiments indicated that eIF1 dissociation is a key step in start codon recognition and that the rate of eIF1 release and its stability in the complex is dependent on the codon in the $\mathrm{P}$ site. Another study demonstrated that the rate constant for phosphate release was more than 100-fold greater in the presence of $\mathrm{mRNA}(\mathrm{AUG})$ than with mRNA (CUC), and 170-fold greater than without mRNA (Algire et al. 2005). The dependence of these steps on base pairing, however, has not yet been investigated. Examining the effects of base-pairing and sequence changes between start codon and anticodon on events downstream in initiation may shed additional light on the mechanism of start codon selection. It will also be of great interest to determine how other factors, for instance eIF3 and eIF4F, as well as structural features of the mRNA, influence the steps of start codon recognition.

\section{MATERIALS AND METHODS}

\section{Reagent preparation}

Purification of 40 S ribosomal subunits and eIFs 1, 1A, and 2, as well as preparation of mRNA and tRNA, was performed as described (Acker et al. 2007).

Wild-type tRNA charged with ${ }^{35} \mathrm{~S}$-Met or with unlabeled methionine (used in chases) was prepared as described (Acker et al. 2007). Initiator tRNAs bearing anticodon changes were made using Dpn mutagenesis (New England Biolabs). Charging of these tRNAs with ${ }^{35} \mathrm{~S}$-Met was complicated by the fact that the yeast methionyl tRNA synthetase (yeast MetRS) recognizes the antico- don as a determinant for charging, and thus in most cases procedural modifications were necessary. $\mathrm{tRNA}_{\mathrm{i}}^{\mathrm{CAG}}$ and $\mathrm{tRNA}_{\mathrm{i}}^{\mathrm{CCU}}$ were charged using the protocol for wild-type tRNA. RNA $_{i}$ CAA was charged using the wild-type protocol with a three-hour incubation instead of a 30-min incubation. The remaining tRNAs bearing anticodon changes were charged using the wild-type protocol with the following modifications: three times the concentration of yeast MetRS, addition of $0.03 \mu \mathrm{M}$ yeast inorganic pyrophosphatase, substitution of $\mathrm{Mn}^{2+}$ for $\mathrm{Mg}^{2+}$, and a one-hour incubation instead of a $30-\mathrm{min}$ incubation. The percentage of ${ }^{35} \mathrm{~S}$ Met incorporated in the charging reaction was $\sim 1 \%-30 \%$ for the changed tRNAs, as compared to $20 \%-50 \%$ for wild-type. Native yeast initiator tRNA used was contained in yeast total tRNA (Roche).

\section{mRNA and tRNA binding experiments}

mRNA competition experiments using pyrene-labeled mRNA were performed essentially as described in Maag et al. (2005). eIFs 1 and 1A were not present except in experiments to determine the effect of their presence, when their concentration was $500 \mathrm{nM}$. The change from the initial value (pyrene-labeled mRNA $\sim 25 \%$ bound to $40 \mathrm{~S}$ subunits in the absence of competitor mRNA) of each observed fluorescence intensity curve was calculated for each point; the data were normalized and subtracted from 1. These data were plotted against the concentration of competitor mRNA and fit with a hyperbolic binding isotherm using Kaleidagraph. To address concerns that contamination of $40 \mathrm{~S}$ subunits with $\mathrm{tRNA}_{\mathrm{i}}$ could produce the differences seen with different codons, excess uncharged $\mathrm{tRNA}_{i}$ was added to the experiment with several mRNAs and no difference was observed (data not shown).

Met-tRNA $A_{i}$ binding to eIF2 was observed using a filter-binding assay as described in Acker et al. (2007). The fraction of MettRNA $_{i}$ bound was plotted versus eIF2•GDPNP concentration and fit with a hyperbolic binding curve (or quadratic binding curve in the case of tight binding) (Kapp and Lorsch 2004a).

\section{Native gels}

43S complex formation was observed on native gels as described (Acker et al. 2007). Factor concentrations were $0.5-1 \mathrm{nM}^{35} \mathrm{~S}$-MettRNA $_{\mathrm{i}}, 200 \mathrm{nM}$ eIF2, $1 \mu \mathrm{M}$ eIF1, and $1 \mu \mathrm{M}$ eIF1A. The concentration of mRNA used was $10 \mu \mathrm{M}$.

\section{Determination of $\mathrm{K}_{d}$ values for TC binding to $40 S$ subunits}

TC was preformed with GDPNP and added to $40 \mathrm{~S} \bullet 1 \bullet 1 \mathrm{~A} \bullet \mathrm{mRNA}$; the mix was incubated for $2 \mathrm{~h}$ at $26^{\circ} \mathrm{C}$ for all mRNAs as well as in the case of no mRNA. Incubating for $16 \mathrm{~h}$ in the no mRNA case did not change the $K_{d}$ value. The fraction of ${ }^{35}$ S-Met-tRNA bound was determined, plotted against $40 \mathrm{~S}$ subunit concentration and fit with a hyperbolic binding curve, or a quadratic binding curve in the case of tight binding.

\section{Kinetics}

Experiments to determine the kinetics of $43 \mathrm{~S}$ complex formation and dissociation were performed essentially as described in Passmore et al. (2007). 
To determine rate constants for TC dissociation from $43 \mathrm{~S}$ complex, 43S•mRNA complex was first formed with ${ }^{35} \mathrm{~S}$-labeled

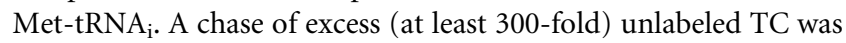
used to make dissociation of the labeled complex irreversible, and the fraction of labeled TC bound was monitored over time on native gels. To test the efficacy of the chase, a "chase first" control was used, where the cold chase was added to $40 \mathrm{~S} \bullet 1 \bullet 1 \mathrm{~A} \bullet \mathrm{mRNA}$ prior to the addition of ${ }^{35} \mathrm{~S}$-labeled TC. With an effective chase, very little labeled TC binds and a low fraction of labeled tRNA bound is observed on the gel. Chase first controls performed after incubation of the chase for $48 \mathrm{~h}$ showed that the chase was stable over the time-course of these experiments. A "mock chase" lacking eIF2 and Met-tRNA $A_{i}$ was employed to check that formation of 43S•mRNA complex was as expected and that the complex did not spontaneously decompose in the absence of chase. Curves were fit to a single exponential, with a floating endpoint. Converging time-courses were employed such that all points in a curve were loaded on the same gel. Three different incubation schemes were used (forming 43S•mRNA for $2 \mathrm{~h}$ before adding chase; forming $43 \mathrm{~S}$ complex for $2 \mathrm{~h}$, then adding mRNA just before the chase; and forming 43S•mRNA for $2 \mathrm{~h}$, at the start of the experiment such that complex formation time varied by time point), and made no significant difference in measured $k_{\text {off- }}$. Increasing the $40 \mathrm{~S}$ concentration from $50 \mathrm{nM}$ to $100 \mathrm{nM}$ in the experiment without mRNA yielded the same rate constant, confirming that the events observed are independent of $40 \mathrm{~S}$ subunit concentration.

To determine rate constants for TC binding to the $40 \mathrm{~S}$ subunit, limiting $(0.5-1 \mathrm{nM}) \mathrm{TC}$ containing ${ }^{35} \mathrm{~S}-\mathrm{Met}_{\mathrm{H}} \mathrm{RNA} \mathrm{A}_{\mathrm{i}}$ was added to a mix containing 40S ribosomes, eIFs 1 and $1 \mathrm{~A}$, and mRNA using a chase of excess (at least 300-fold) unlabeled TC to stop observed association at the desired time point (Rose 1980). Time points were loaded onto a running native gel within minutes after addition of the chase, such that given the slow rate constants for TC dissociation, dissociation of labeled TC in the chase prior to gel loading was negligible. We observed the rate of TC binding to the $40 \mathrm{~S}$ subunit at several different $40 \mathrm{~S}$ concentrations. The observed rate constants were plotted versus $40 \mathrm{~S}$ concentration and fit to a line to determine the $k_{\text {on }}$.

\section{In vivo dual luciferase assay}

The dual luciferase assay was performed as in Cheung et al. (2007). Briefly, renilla and firefly luciferase mRNAs were expressed from a single plasmid as independent transcripts in yeast (BY4741 or $u p f 1 \Delta$ ), and enzyme activities measured in a Turner Biosystems Modulus Microplate reader. The ratio of renilla activity, in relative light units, to firefly activity was calculated for each sample. The renilla message, with an AUG start codon, acts as an internal control for measuring the translation from the firefly message, with an AUG or near-cognate (XXX) start codon. The ratio of firefly luciferase activities, XXX/ $\mathrm{AUG}\left[\left(F_{\mathrm{XXX}} / R_{\mathrm{AUG}}\right) /\left(F_{\mathrm{AUG}} / R_{\mathrm{AUG}}\right)\right]$, is used to quantify translation from a near-cognate start codon of firefly luciferase relative to an AUG start codon.

\section{ACKNOWLEDGMENTS}

We thank Kristian Baker for the upfls yeast strain and Sarah Mitchell, Seth Dickey, and Alan Hinnebusch for helpful discussions and comments on the manuscript. This work was supported by grants from the American Heart Association (0555466U) and NIH (GM62128) to J.R.L. Development of the dual luciferase assay was supported by NIH grant (DK078633) to J.R.L.

Received August 18, 2008; accepted October 3, 2008.

\section{REFERENCES}

Acker, M.G., Kolitz, S.E., Mitchell, S.F., Nanda, J.S., and Lorsch, J.R. 2007. Reconstitution of yeast translation initiation. Methods Enzymol. 430: 111-145.

Algire, M.A. and Lorsch, J.R. 2006. Where to begin? The mechanism of translation initiation codon selection in eukaryotes. Curr. Opin. Chem. Biol. 10: 480-486.

Algire, M.A., Maag, D., and Lorsch, J.R. 2005. $\mathrm{P}_{\mathrm{i}}$ release from eIF2, not GTP hydrolysis, is the step controlled by start-site selection during eukaryotic translation initiation. Mol. Cell 20: 251-262.

Algire, M.A., Maag, D., Savio, P., Acker, M.G., Tarun, S.Z., Sachs, A.B., Asano, K., Nielsen, K.H., Olsen, D.S., Phan, L., et al. 2002. Development and characterization of a reconstituted yeast translation initiation system. RNA 8: 382-397.

Barraud, P., Schmitt, E., Mechulam, Y., Dardel, F., and Tisné, C. 2008. A unique conformation of the anticodon stem-loop is associated with the capacity of tRNA $\mathrm{f}_{\mathrm{fet}}$ to initiate protein synthesis. Nucleic Acids Res. 36: 4894-4901.

Cheung, Y.N., Maag, D., Mitchell, S.F., Fekete, C.A., Algire, M.A., Takacs, J.E., Shirokikh, N., Pestova, T., Lorsch, J.R., and Hinnebusch, A.G. 2007. Dissociation of eIF1 from the $40 \mathrm{~S}$ ribosomal subunit is a key step in start codon selection in vivo. Genes \& Dev. 21: 1217-1230.

Cigan, A.M., Feng, L., and Donahue, T.F. 1988. RRNA $_{i}^{\text {Met }}$ functions in directing the scanning ribosome to the start site of translation. Science 242: 93-97.

Clements, J.M., Laz, T.M., and Sherman, F. 1988. Efficiency of translation initiation by non-AUG codons in Saccharomyces cerevisiae. Mol. Cell. Biol. 8: 4533-4536.

Crick, F.H. 1966. Codon-anticodon pairing: The wobble hypothesis. J. Mol. Biol. 19: 548-555.

Culbertson, M.R. and Neeno-Eckwall, E. 2005. Transcript selection and the recruitment of mRNA decay factors for NMD in Saccharomyces cerevisiae. RNA 11: 1333-1339.

Donahue, T.F. and Cigan, A.M. 1988. Genetic selection for mutations that reduce or abolish ribosomal recognition of the HIS4 translational initiator region. Mol. Cell. Biol. 8: 2955-2963.

Drabkin, H.J. and RajBhandary, U.L. 1998. Initiation of protein synthesis in mammalian cells with codons other than AUG and amino acids other than methionine. Mol. Cell. Biol. 18: 51405147.

Fekete, C.A., Mitchell, S.F., Cherkasova, V.A., Applefield, D., Algire, M.A., Maag, D., Saini, A.K., Lorsch, J.R., and Hinnebusch, A.G. 2007. N- and C-terminal residues of eIF1A have opposing effects on the fidelity of start codon selection. EMBO J. 26: 1602-1614.

Hinnebusch, A.G. 2005. Translational regulation of GCN4 and the general amino acid control of yeast. Annu. Rev. Microbiol. 59: 407450 .

Johnson, K.A. 1992. Transient-state kinetic analysis of enzyme reaction pathways. In The enzymes (ed. D.S. Sigman), pp. 1-61. Academic, New York.

Kapp, L.D., Kolitz, S.E., and Lorsch, J.R. 2006. Yeast initiator tRNA identity elements cooperate to influence multiple steps of translation initiation. RNA 12: 751-764.

Kapp, L.D. and Lorsch, J.R. 2004a. GTP-dependent recognition of the methionine moiety on initiator tRNA by translation factor eIF2. $J$. Mol. Biol. 335: 923-936.

Kapp, L.D. and Lorsch, J.R. 2004b. The molecular mechanics of eukaryotic translation. Annu. Rev. Biochem. 73: 657-704. 
Kierzek, R., Burkard, M.E., and Turner, D.H. 1999. Thermodynamics of single mismatches in RNA duplexes. Biochemistry 38: 1421414223 .

Kozak, M. 1978. How do eukaryotic ribosomes select initiation regions in messenger RNA? Cell 15: 1109-1123.

Kozak, M. 1986. Point mutations define a sequence flanking the AUG initiator codon that modulates translation by eukaryotic ribosomes. Cell 44: 283-292.

Kozak, M. 2002. Pushing the limits of the scanning mechanism for initiation of translation. Gene 299: 1-34.

Lomakin, I.B., Shirokikh, N.E., Yusupov, M.M., Hellen, C.U., and Pestova, T.V. 2006. The fidelity of translation initiation: Reciprocal activities of eIF1, IF3, and YciH. EMBO J. 25: 196210.

Maag, D., Algire, M.A., and Lorsch, J.R. 2006. Communication between eukaryotic translation initiation factors 5 and $1 \mathrm{~A}$ within the ribosomal preinitiation complex plays a role in start site selection. J. Mol. Biol. 356: 724-737.

Maag, D., Fekete, C.A., Gryczynski, Z., and Lorsch, J.R. 2005. A conformational change in the eukaryotic translation preinitiation complex and release of eIF1 signal recognition of the start codon. Mol. Cell 17: 265-275.

Macey, R., Oster, G., and Zahnley, T. 2000. Berkeley Madonna. University of California at Berkeley, Berkeley, CA.

Mitchell, S.F. and Lorsch, J.R. 2008. Should I stay or should I go? Eukaryotic translation initiation factors 1 and $1 \mathrm{~A}$ control start codon recognition. J. Biol. Chem. 283: 27345-27349.

Passmore, L.A., Schmeing, T.M., Maag, D., Applefield, D.J., Acker, M.G., Algire, M.A., Lorsch, J.R., and Ramakrishnan, V. 2007. The eukaryotic translation initiation factors eIF1 and eIF1A induce an open conformation of the $40 \mathrm{~S}$ ribosome. Mol. Cell 26: 41-50.

Peabody, D.S. 1989. Translation initiation at non-AUG triplets in mammalian cells. J. Biol. Chem. 264: 5031-5035.

Pestova, T., Lorsch, J.R., and Hellen, C. 2007. The mechanism of translation initiation in eukaryotes. In Translational control in biology and medicine (eds. M.B. Mathews et al.), pp. 87-128. Cold Spring Harbor Laboratory Press, Cold Spring Harbor, NY.
Pestova, T.V., Borukhov, S.I., and Hellen, C.U. 1998. Eukaryotic ribosomes require initiation factors 1 and $1 \mathrm{~A}$ to locate initiation codons. Nature 394: 854-859.

Pestova, T.V. and Kolupaeva, V.G. 2002. The roles of individual eukaryotic translation initiation factors in ribosomal scanning and initiation codon selection. Genes \& Dev. 16: 2906-2922.

Pisarev, A.V., Kolupaeva, V.G., Pisareva, V.P., Merrick, W.C., Hellen, C.U., and Pestova, T.V. 2006. Specific functional interactions of nucleotides at key -3 and +4 positions flanking the initiation codon with components of the mammalian $48 \mathrm{~S}$ translation initiation complex. Genes \& Dev. 20: 624-636.

Rose, I.A. 1980. The isotope trapping method: Desorption rates of productive E.S complexes. Methods Enzymol. 64: 47-59.

Schmitt, E., Blanquet, S., and Mechulam, Y. 2002. The large subunit of initiation factor aIF2 is a close structural homologue of elongation factors. $E M B O$ J. 21: 1821-1832.

Selmer, M., Dunham, C.M., Murphy 4th., F.V., Weixlbaumer, A., Petry, S., Kelley, A.C., Weir, J.R., and Ramakrishnan, V. 2006. Structure of the 70S ribosome complexed with mRNA and tRNA. Science 313: 1935-1942.

Studer, S.M., Feinberg, J.S., and Joseph, S. 2003. Rapid kinetic analysis of EF-G-dependent mRNA translocation in the ribosome. J. Mol. Biol. 327: 369-381.

Valásek, L., Nielsen, K.H., Zhang, F., Fekete, C.A., and Hinnebusch, A.G. 2004. Interactions of eukaryotic translation initiation factor 3 (eIF3) subunit NIP1/c with eIF1 and eIF5 promote preinitiation complex assembly and regulate start codon selection. Mol. Cell. Biol. 24: 9437-9455.

Wang, S., Friedman, A.E., and Kool, E.T. 1995. Origins of high sequence selectivity: A stopped-flow kinetics study of DNA/RNA hybridization by duplex- and triplex-forming oligonucleotides. Biochemistry 34: 9774-9784.

Woo, N.H., Roe, B.A., and Rich, A. 1980. Three-dimensional structure of Escherichia coli initiator tRNA ${ }_{\mathrm{f}}^{\text {Met }}$. Nature 286: 346-351.

Yoon, K., Turner, D.H., Tinoco Jr., I., Haar, F., and Cramer, F. 1976. The kinetics of binding of U-U-C-A to a dodecanucleotide anticodon fragment from yeast tRNA-Phe. Nucleic Acids Res. 3: 2233-2241. 

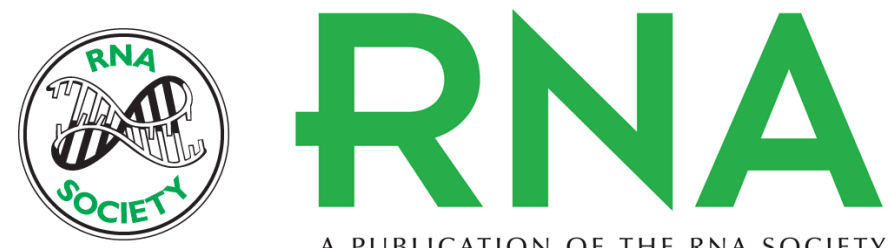

A PUBLICATION OF THE RNA SOCIETY

\section{Kinetic and thermodynamic analysis of the role of start codon/anticodon base pairing during eukaryotic translation initiation}

Sarah E. Kolitz, Julie E. Takacs and Jon R. Lorsch

RNA 2009 15: 138-152 originally published online November 24, 2008

Access the most recent version at doi:10.1261/rna.1318509

\section{References This article cites 38 articles, 15 of which can be accessed free at: http://rnajournal.cshlp.org/content/15/1/138.full.htmI\#ref-list-1}

License Email Alerting $\begin{aligned} & \text { Receive free email alerts when new articles cite this article - sign up in the box at the } \\ & \text { Service }\end{aligned}$ top right corner of the article or click here. 